\title{
Ilhas oceânicas brasileiras e suas relações com a tectônica atlântica
}

\author{
Fernando Flávio Marques de Almeida \\ Departamento de Minas e Metalurgia \\ Escola Politécnica (aposentado) - Universidade de São Paulo \\ ffma@uol.com.br
}

* Este documento deve ser referido como segue:

Sintetizam-se conhecimentos modernos sobre as ilhas e arquipélagos oceânicos brasileiros, cuja origem e localização geográfica sofreu decisiva influência de estruturas da litosfera oceânica. Reúnem-se informações sobre a geologia das ilhas e a nomenclatura recente, química e mineralógica, de suas rochas. É sugestiva a influência de hotspots na evolução de zonas de fratura, originando cadeias vulcânicas e ilhas. No Ceará a atuação de hotspot suposto astenosférico, na extensão ao continente de zona de fratura reativada, desenvolveu estruturas, magmatismo alcalino, alto fluxo térmico e sismicidade. Penetrando nas fraturas reativadas dessa zona no oceano, com o deslizamento da placa formou-se uma cadeia vulcânica, em cuja extremidade está o Arquipélago de Fernando de Noronha. Essa evolução é similar à da Ilha de Trindade e Arquipélago Martin Vaz, que constituem o topo emerso de grandes montes vulcânicos do extremo oriental das duas cadeias, situadas em zona de fratura que penetra na borda do continente. O estranho Aarquipélago de São Pedro e São Paulo possui origem inteiramente diversa, pois emerge no trecho transformante ativo de uma cadeia de zona de fratura onde esta secciona o rift-valley axial da Dorsal Meso-Atlântica, expondo-se uma protrusão de rochas mantélicas sem vulcânicas emersas aflorantes, embora as existam submersas.

PALAVRAS-CHAVE zona de fratura, hotspot, Placa Sul-Americana, vulcanismo.

ABSTRACT

The Brazilian oceanic islands and relationships with the Atlantic tectonics. A synthesis of modern knowledge on the Brazilian oceanic islands and archipelagoes shows that the oceanic lithosphere have influenced their origin and geographic situation. Distribution, allignment and age of the volcanic chains evidence a relationship between the origin of islands and archipelagoes and the activity of hotspots along fracture zones. At the Ceara coast, in the extension to the continent of a reactivated zone of oceanic breaking, typical structures, alkaline magmatism, high thermal flow and sismicity result from the influence of a hotspot, presumed to be astenospheric. A volcanic chain is formed as the plate is displaced and the reactivated breakings penetrate the ocean. The Fernando de Noronha Archipelago is at the end of the fracture zone. A similar evolution would have originated the Island of Trindade and the Archipelago Martin Vaz, that constitute the eastern emerged top of two chains of great volcanic mountains. The strange Archipelago of São Pedro and São Paulo is of a quite different origin, because it emerges on an active transforming segment of a fracture zone chain where it cuts the axial rift-valley of the Meso-Atlantic Ridge, exposing a protrusion of volcanic mantle rocks without exposed volcanic rocks, but they exist submerged.

KEYWORDS fracture zone, hotspot, South-American Plate, volcanism, Brazil. 


\section{Introdução}

Com a ruptura da Terra de Gondwana e a conseqüente separação das placas litosféricas da América do Sul e da África surgiu o Oceano Atlântico equatorial e meridional. Em sua região mediana, onde as duas placas divergem devido ao acréscimo de nova crosta oceânica, elevou-se a Dorsal Médio-Atlântica. Na região axial dessa cadeia desenvolveu-se um vale de rifte, sítio de surgimento do magma basáltico. Esse rifte é seccionado por

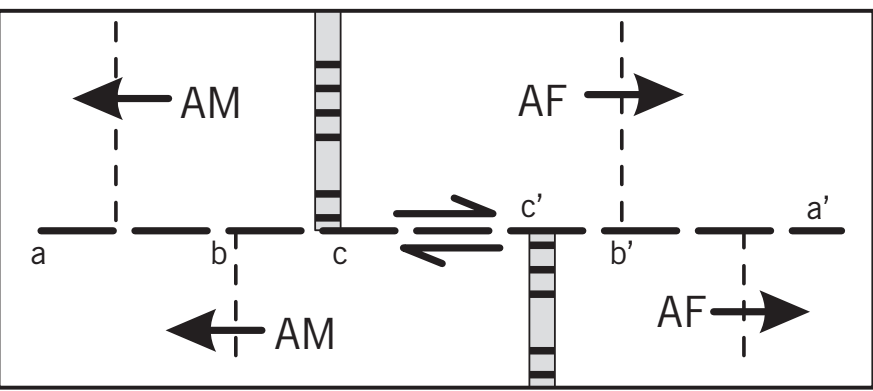

Figura 1 - Modelo de dois segmentos consecutivos do rifte axial da Dorsal Médio-Atlântica, separados por uma falha transformante c-c' nas extremidades da qual se desenvolvem os segmentos da zona de fratura ac e a'c' (baseado em Wilson 1965) falhas transformantes (Wilson 1965), presentes e ativas entre dois de seus segmentos consecutivos (Fig. 1). Com o prosseguir do espalhamento da crosta nela subsistem os traços inativos deixados pelas falhas transformantes pretéritas. Esses traços constituem as zonas de fratura, que nas maiores do Atlântico Sul podem ser duplas, triplas ou mesmo quádruplas (Cande et al. 1988), quando podem ultrapassar $200 \mathrm{~km}$ de largura total, como na do Rio Grande. Podem constituir relevos por vezes importantes e representam faixas de fraqueza da litosfera oceânica. Se em sua deriva a placa passar sobre um hotspot [ponto-quente] ou uma pluma mantélica, podem atuar como conduto de magma formador de vulcões, que emersos se apresentam como ilhas. Quando inativos acabam sendo arrasados pela erosão marinha e subaérea, transformando-se em bancos submarinos de topo truncado pela erosão, os chamados guyots (Hess 1946) ou ainda podem suportar atolls mais ou menos profundamente submersos (Menard 1984). Procuraremos descrever resumidamente a estrutura atualizada das ilhas oceânicas brasileiras e as relações genéticas que apresentam com essas grandes feições tectônicas da crosta oceânica.

Fazem parte do território nacional cinco ilhas e arquipélagos implantados no assoalho oceânico: arquipélagos de São Pedro e São Paulo, de Fernando de Noronha e atol das Rocas, todos na região equatorial; ilha da Trindade e arquipélago de Martin Vaz na região tropical (Fig. 2). Quais suas estruturas, quando e como surgiram, por que ocupam suas posições geográficas no Atlântico e que relações têm com a tectônica da crosta oceânica, tal é o tema desta exposição.

Figura 2 - Localização das ilhas e arquipélagos oceânicos brasileiros e distâncias das capitais mais próximas 


\section{Arquipélago de São Pedro e de São Paulo}

O Arquipélago de São Pedro e São Paulo (ASPSP) situa-se a pouco menos de um grau a norte do Círculo Equatorial e a $29^{\circ} 20^{\prime} \mathrm{W}$, distando cerca de 1.000 $\mathrm{km}$ a NE de Natal. Seu condicionamento tectônico é especial, pois se inclui no trecho de falhas transformantes ativas da grande Zona de Fratura São Paulo que atravessa todo o oceano, próximo de onde ela secciona o rift-valley axial da Dorsal Médio-Atlântica (Fig. 3). A zona de fratura, aí com cerca de $120 \mathrm{~km}$ de largura, rompeu e arrastou-o cerca de $580 \mathrm{~km}$ com movimento sinistral. Ela se compõe de uma série de cadeias e sulcos devidos a falhas (Hekinian et al. 2000). O arquipélago consiste de quatro pequenas ilhas e rochedos emersos no cimo de uma cadeia de forma sigmoidal situada junto à borda norte da zona de fratura, afastada cerca de $90 \mathrm{~km}$ a leste do local onde esta secciona o vale de rifte. Não longe do arquipélago, a SW, as profundidades alcançam
$5.000 \mathrm{~m}$. A esse posicionamento tectônico muito especial o ASPSP deve suas principais características: natureza e grande idade de suas rochas magmáticas, sua procedência e a intensa atividade sísmica local.

O arquipélago é um conjunto de quatro pequenas ilhas e rochas que, de acordo com Campos et al. (2005) ocupam área total emersa de \pm 17.000 $\mathrm{m}^{2}$. A distância entre seus pontos extremos não ultrapassa $420 \mathrm{~m}$ e o pico mais alto é de tão somente $18 \mathrm{~m}$, segundo esses autores, que realizaram um esboço geológico do arquipélago em escala 1:500.

O ASPSP é formado por rochas peridotíticas milonitizadas, variadamente serpentinizadas, penetradas diapiricamente [protrudidas] a partir do manto (Melson et al. 1972), na zona de falhas transformantes ativas (Bonatti 1973, 1976; Hekinian et al. 2000). Gorini e Carvalho (1984) referem terem sido determinadas idades isotópicas de $4.500 \mathrm{Ma}$ e 835 Ma para rochas do arquipélago, mas não citam a fonte dessas datações. Esta segunda idade é referida

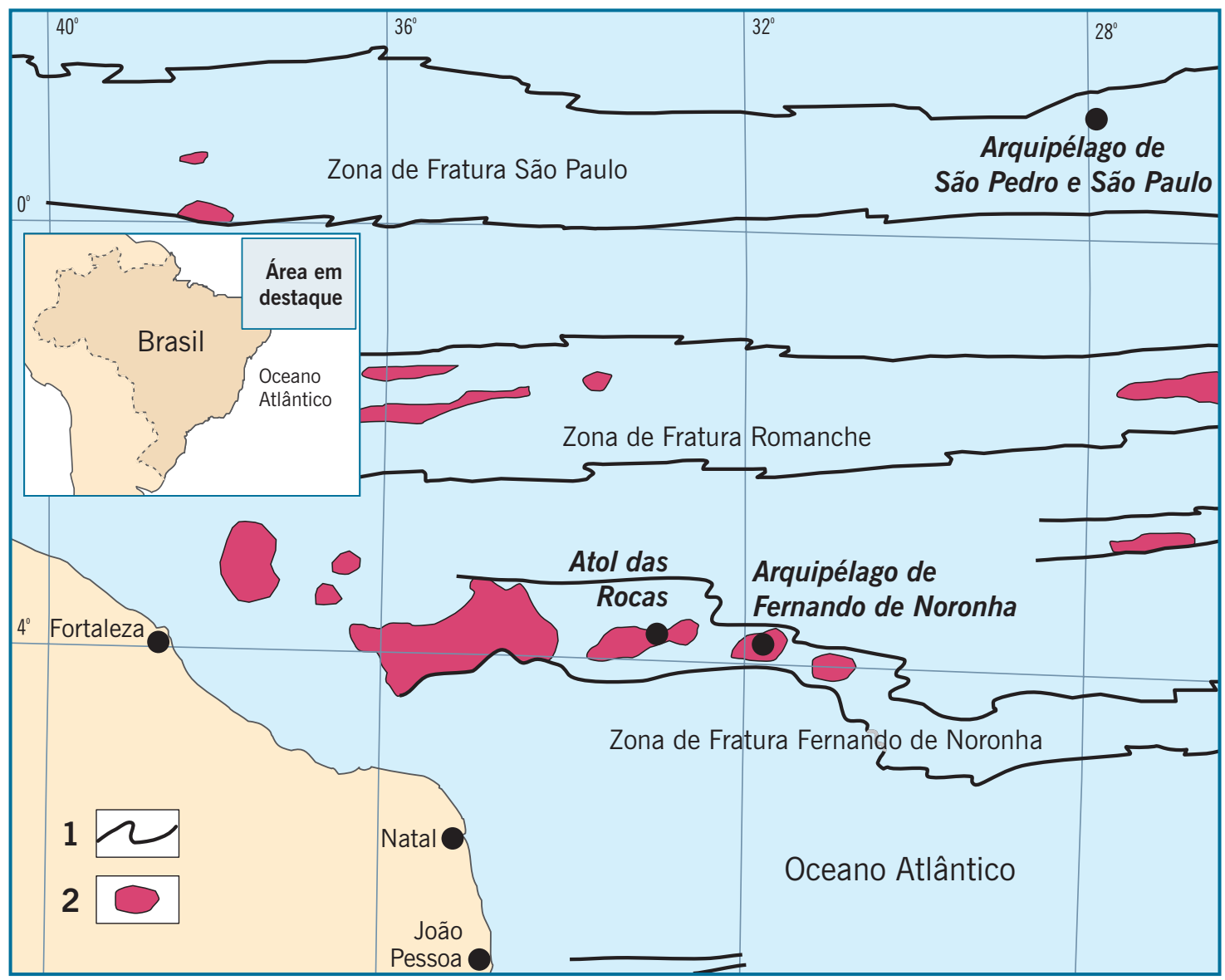

Figura 3 - Região oceânica adjacente ao Nordeste brasileiro: situação do Arquipélago de São Pedro e São Paulo na Zona de Fratura São Paulo; Atol das Rocas e Arquipélago de Fernando de Noronha, na extremidade da Zona de Fratura Fernando de Noronha. 1 - Limite de zonas de fratura; 2 - Rochas magmáticas 
por Melson et al. 1972 como obtida por K/Ar em hornblenda milonito de uma protrusão ultrabásica emergente na ilha, mas Bonatti julga-a inconsistente com o esquema clássico do espalhamento da crosta oceânica em zonas transformantes. No arquipélago não se expõem rochas vulcânicas, mas derrames recentes de basalto e diques de diabásio e gabro foram reconhecidos nas áreas submersas do maciço que o suporta, pesquisadas em submarino (Hekinian et al. 2000). Permanece hipotético o mecanismo de instalação do maciço peridotítico mantélico.

No interior da ilha Challenger subsistem restos de uma pequena bacia sedimentar marinha de idade quaternária, de águas rasas contendo camadas compostas de clásticos polimíticos de origem bioclástica e grãos de rochas do embasamento. Foram originalmente definidas (Campos et al. 2002) sob a denominação de Formação São Pedro e São Paulo. Acham-se mapeadas em trabalho de Campos et al. (2005), que nela reconheceram duas unidades. A inferior, denominada Atobás, é de natureza conglomerática, formada por seixos arredondados pela ação das ondas. No alto, a unidade é constituída de areia grossa com seixos. As camadas foram tectonicamente basculadas, após o que se iniciou a deposição da Unidade Viuvinhas, constituída de arenito cinza contendo blocos de dimensões até decimétricas, resultados provavelmente, de acordo com Campos et al. (2005), da atividade sísmica, intensa na região. Continuou-se a sedimentação arenosa em ambiente mais calmo. Um novo evento tectônico basculou toda a Formação São Pedro

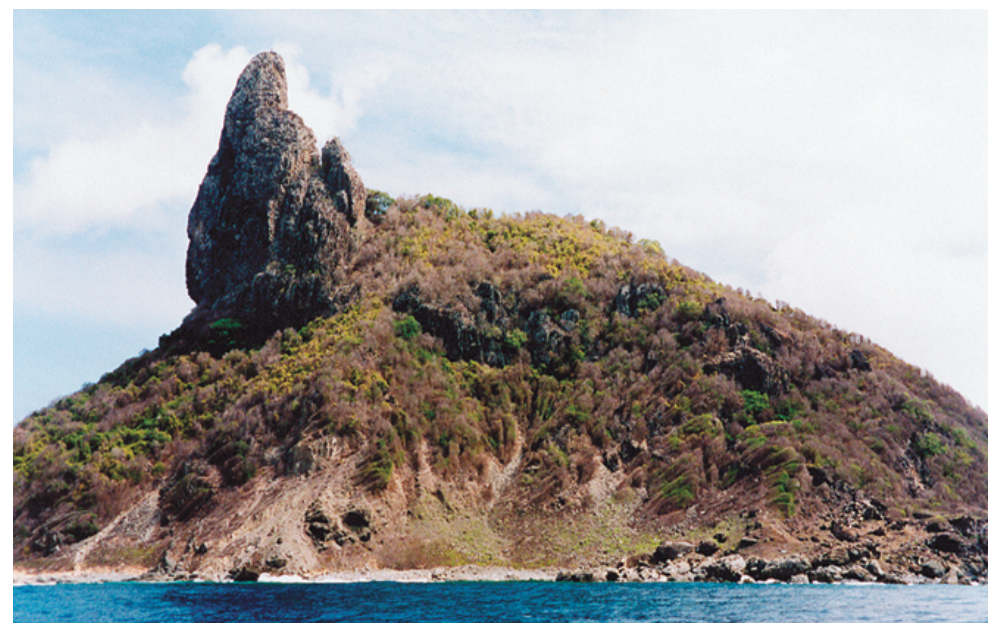

Figura 4 - Morro do Pico, resto de erosão de um grande domo fonolítico. Esse testemunho, a maior elevação do arquipélago, vem-se desfazendo pela queda de blocos das juntas verticais do domo. (Foto Ulbrich et al. 2004) e São Paulo. Segundo estes autores o arquipélago encontrava-se abaixo do atual nível do mar durante o início do Neógeno Superior.

\section{Arquipélago de Fernando de Noronha}

O Arquipélago de Fernando de Noronha, que pesquisamos em três ocasiões na década de 1950, situase a $4^{\circ} \mathrm{S}$ e $32^{\circ} \mathrm{W}$, a $360 \mathrm{~km}$ a NE de Natal, na extremidade oriental de uma cadeia de montes submarinos orientada a leste-oeste que identificamos em 1955 pelo exame de cartas batimétricas do Ministério da Marinha do Brasil. Vários desses montes tiveram seus cimos arrasados pela erosão subaérea e abrasão marinha. Hoje se apresentam como guyots, cobertos de calcários biogênicos, achando-se a menos de $100 \mathrm{~m}$ de profundidade. O monte mais novo, ainda em parte emerso (Figs. 4 e 5), suporta o arquipélago, no qual o vulcanismo se extinguiu há cerca de 1,8 Ma (Cordani 1970). O Atol de Rocas é um de tais bancos que teve sua plataforma de abrasão marinha coberta por depósitos biogênicos hoje expostos. Outros montes e elevações do embasamento presumivelmente magmáticos, apresentamse nessa zona de fratura da crosta oceânica compondo o conjunto a Cadeia Fernando de Noronha, (Fig. 3) assim denominada por Gorini e Bryan em 1974. Para Gorini e Bryan (1976) ela aparenta ser a contraparte da Zona de Fratura Jean Charcot que se estende ao delta do Niger na África, mas outros supuseram-na corresponder à Zona de Fratura Chain (v.g. Bryan et al. 1972). A cadeia se constitui por feições tectônicas e produtos de vulcanismo alcalino. Junto ao embasamento continental ao largo de Fortaleza acha-se o Guyot do Ceará, um banco vulcânico, alto de mais de 2.000 metros, cujo topo aplainado pela erosão, com reduzida cobertura sedimentar, situa-se entre 300 e 250 metros de profundidade (Guazelli e Costa 1978). O trecho oceânico da cadeia, entre este guyot e o arquipélago, tem $650 \mathrm{~km}$. A zona de fratura em que ela viria a surgir estende-se à margem continental do Ceará. Em seu trecho submerso, na plataforma continental a ela é atribuído o Alto de Fortaleza, extensão coberta 
de rochas pré-cambrianas que separa a bacia do Ceará do prolongamento ocidental offshore da Bacia Potiguar. Na margem emersa relacionamos à cadeia o domo fonolítico de Caruru [Cararu, como verificamos recentemente também ser conhecido no local], a leste de Mecejana, a primeira ocorrência identificada desse distrito alcalino que em 1988 denominamos Vulcanismo Mecejana. Sua semelhança com rochas do arquipélago de Fernando de Noronha foi noticiada por Almeida em 1955, que o incluiu na cadeia vulcânica ${ }^{1}$, com o que a estendeu à margem continental emersa do Ceará. Esse fonólito foi petrograficamente descrito por Vandoros e Oliveira em 1968 e datado por Cordani em 1970 em 29,9 $\pm 0,9$ Ma. Posteriormente novas ocorrências dessas alcalinas foram descobertas e classificadas. Dispersam-se a sul e no quadrante SW de Fortaleza, distantes desta cidade até cerca de 75 quilômetros (Rao e Sial 1972, Braga et al. 1981, Nascimento et al. 1981, Guimarães et al. 1982, Sial 1987, Macciotta et al. 1990). Constituem uma dezena de plugs e domos de rochas alcalifonolíticas, tefríticas e fonotefríticas, várias delas salientando-se no baixo relevo da superfície de aplainamento de Fortaleza, além de piroclastos locais e numerosos diques de alcalinas. Algumas formam relevo destacado, como o neck de alcalifonólito do morro cônico Pão de Açúcar. Diversas datações pelos métodos K/Ar, $\mathrm{Rb} / \mathrm{Sr}$ em rocha total e isócrona de referência $\mathrm{Rb} /$ Sr (Cordani 1970, Teixeira et al. 1978, Braga et al. 1981, Nascimento et al. 1981, Guimarães 1982), acusaram valores entre $36 \pm 2$ a $29,9 \pm 0,9 \mathrm{Ma}$, conferindo idade eocena superior a oligocena antiga para o distrito alcalino. Contudo, Mizusaki e Saracchini (1991) referiram posteriormente uma dupla determinação de idade K/Ar em feldspato de brecha toleítica da plataforma continental a noroeste de Fortaleza acusando valores de $43 \pm 12$ e 44 $\pm 03 \mathrm{Ma}$, que tomamos como a mais antiga ora conhecida do distrito alcalino de Fortaleza. Outra determinação em rocha total de diabásio (transicional/ alcalino?) acusou $83 \pm 06 \mathrm{Ma}$, valor tão discrepante das demais idades desse distrito magmático que não o consideramos a ele pertencente. Sugerimos que esta rocha, também ocorrente na plataforma continental próximo de Fortaleza, represente o pulso

1 Almeida (1955) não considerou quaternária a idade da rocha alcalina de Mecejana como refere Sykes (1978). Ela já havia sido datada por Cordani ao ser publicado o Mapa Geológico do Brasil em escala 1:5.000.000, ano 1971, coordenado por Almeida. magmático que acompanhou a reativação tectonomagmática (Mizusaki 1998) decorrente da separação final da América do Sul e África há cerca de 90 milhões de anos, no Cenomaniano/Turoniano.

Rochas vulcânicas efusivas, basaltos de natureza química e petrográfica então pouco conhecidas, foram perfuradas pela Petrobrás acima de camadas cretáceas na sub-bacia de Mundaú, trecho oriental da bacia do Ceará, e intrusões alcalinas no Alto de Fortaleza a norte da cidade. Foram relatadas originalmente por Thomaz Filho (1983), que também indicou sua idade de $32 \pm 1 \mathrm{Ma}$, e por Miranda et al. (1986). Almeida et al. (1988) haviam denominado provisoriamente esses derrames e intrusões como Vulcanismo Mundaú. Hoje supomos que, por sua idade e posição tectônica, também pertençam ao Vulcanismo Mecejana. A área em que se incluem essas alcalinas é uma das duas que apresentam maior fluxo térmico $\left(200 \mathrm{~mW} / \mathrm{m}^{2}\right)$, maior gradiente geotérmico $\left(60-80^{\circ} \mathrm{C} / \mathrm{km}\right)$ do Nordeste Oriental, e não por acaso, acha-se contida na chamada Zona Sísmica de Fortaleza (Carneiro et al. 1989), que aproximadamente coincide com o distrito alcalino homônimo.

Costa et al. (2002) baseados no exame de campo e de imagens orbitais, reconheceram na região costeira entre Fortaleza e Acaraú um sistema de falhas e fraturas que segundo eles caracterizam uma tectônica transcorrente de orientação E-W, que se coaduna com o que seria esperado durante a abertura do Oceano Atlântico no contexto transcorrente/ transformante destral de que se originou a margem continental atlântica no setor equatorial. As observações desses autores parecem confirmar a extensão, à margem do continente, da Zona de Fratura Fernando de Noronha, já antes sugerida pela presença do distrito alcalino de Fortaleza. Constitui esse distrito tectono-magmático ótimo exemplo da extensão de uma zona de fratura oceânica à litosfera continental, com desenvolvimento de magmatismo alcalino e sismicidade, tal como outros apontados por Sykes (1978). Esse autor julga mais satisfatória a explicação de as zonas continentais de terremotos e magmatismo alcalino situaremse em antigas zonas de fraqueza da última grande orogenia, o que não é o caso da província sismomagmática de Fortaleza.

Diversos autores que estudaram a petrografia, mineralogia e geoquímica de rochas desse pequeno distrito magmático salientaram sua semelhança com as congêneres do arquipélago. A cadeia vulcânica assim definida, e sua continuidade ao continente, 
têm extensão de cerca de $750 \mathrm{~km}$. Inclui-se na Zona de Fratura Fernando de Noronha que se continua para leste do arquipélago. Fodor et al. (1998) compararam a composição isotópica e de elementos traços de basaltos alcalinos do Rio Grande do Norte e São Pedro (Pernambuco) emitidas entre \pm 30 e $13 \mathrm{Ma}$ verificando serem geralmente similares às das lavas emitidas no arquipélago entre 12 e $2 \mathrm{Ma}$ passados, pelo que atribuíram todos à chamada pluma de Fernando de Noronha. Entretanto, a hipótese das plumas mantélicas de procedência profunda proposta por Morgan (1971), que tem sido amplamente aceita, vem sendo recentemente questionada, como historiado por Ernesto (2005). Essa pesquisadora reconstituiu a posição da América do Sul para 130, 80 e 50 Ma passados, levando em consideração a posição aparente dos pólos magnéticos a partir do Cretáceo Inferior $( \pm 120 \mathrm{Ma})$, das rochas alcalinas brasileiras e algumas outras do continente, assim como as anomalias magnéticas da crosta oceânica. Admitiu que se os hotspots fossem fixos no manto profundo e levando em consideração que mesmo se a área de atuação da suposta pluma de Fernando de Noronha tivesse $\pm 1000 \mathrm{~km}$ de raio não existiria possibilidade de relacionamento do vulcanismo desse arquipélago com a província alcalina do Nordeste como proposto por Fodor et al. (1998) Segundo Ernesto (2005) o mesmo valeria para a suposta pluma da Ilha da Trindade em relação ao magmatismo neocretáceo da Serra do Mar, Iporá e Alto Paranaíba (Gibson et al. 1995), pois ambas as regiões estariam fora da área de atuação dessas plumas, a menos que se admitisse a hipótese de uma pluma mantélica quente poder se deslocar centenas de quilômetros de sua posição de impacto inicial, como foi suposto em 1998 por Thompson e colaboradores para o movimento (aparente) da pluma de Trindade, que teria partido do Centro-Oeste brasileiro há $85 \mathrm{Ma}$, causado o magmatismo alcalino das regiões de Iporá, Alto Paranaíba e Serra do Mar antes de alcançar Trindade-Martin Vaz, onde se encontraria. Anderson (2000) julgou desnecessária a hipótese de plumas no manto profundo das quais se elevariam hotspots, pois diversos fatores geofísicos que cita são causadores de elevações locais de temperatura abaixo das placas litosféricas, de até $\pm 150^{\circ} \mathrm{C}$ a $\pm 200^{\circ} \mathrm{C}$, de tal modo podendo originar frações fundidas capazes de formar hotspots no manto superior. Também Courtillot et al. (2003) consideraram que nem todos os hotspots originam-se em plumas mantélicas profundas, mas podem ser feições do manto superior, ligadas à astenosfera como réplicas passivas das formas de rompimento litosférico. São do tipo que denominaram andersoniano. Supomos que tal seria o de Fernando de Noronha.

Em consonância com as considerações acima sugerimos que em meados do Eoceno um hotspot teria surgido na região de Fortaleza, ao longo da borda afinada e fraturada da crosta continental em contato com a oceânica, originado por anomalia térmica na astenosfera induzida pela cinemática litosférica. O hotspot teria produzido o vulcanismo representado pelas rochas alcalinas que se expõem nesse distrito magmático. Não se conhecem indícios de que esse hotspot tivesse existência pretérita, tendo atuado em sítio que estaria hoje localizado mais para o interior do continente ou no oceano, e a suposição de que por ele tivesse passado a região de Louisiana, sul da Flórida, há 180 Ma (Morgan 1983) parece-nos altamente especulativa. Com o prosseguir da deriva da placa para oeste esse ponto-quente teria dado origem à cadeia vulcânica marinha, realizando-se a infiltração do magma em fraturas litosféricas presentes na Zona de Fratura Fernando de Noronha, que adentra a margem continental emersa na região de Fortaleza. Estas fraturas possivelmente foram reativadas com a alteração da rotação do continente quando, segundo reconstrução paleomagnética de Ernesto (2005), ele mudou o sentido horário inicial para anti-horário e passou a se deslocar para norte em direção à sua latitude atual, fenômeno que certamente produziu deformações na placa. Também Sadowski (1987) postulou ter a mudança do pólo de rotação havida há cerca de $38 \mathrm{Ma}$, durante o Eoceno Médio, causado um pulso importante na ativação tectono-magmática na América do Sul e na África. Esse fenômeno causador de mudanças no movimento das placas no Atlântico Sul, segundo Cande et al. (1988) aparenta correlacionar-se a uma reorganização global das placas havida no Eoceno Médio, ocasião em que, não por coincidência, se iniciou o vulcanismo na província alcalina de Fortaleza e na bacia Potiguar há cerca de $40 \mathrm{Ma}$. Encerrou-se a atuação do ponto-quente no arquipélago, ou num monte submarino existente na mesma zona de fratura situado a $60 \mathrm{~km}$ a ESE, no final do Plioceno, seja por dele se ter desviado o ponto quente ou a zona de fratura, ou pela perda de sua atividade. Considerando-se a distância de $\pm 750 \mathrm{~km}$ do distrito alcalino continental à ilha Fernando de Noronha e a idade mais antiga conhecida das alcalinas desta e de Fortaleza é possível deduzir a 
velocidade média de 23,4 km/Ma para o deslocamento para oeste da placa Sul-Americana na região equatorial, entre o Eoceno Médio e o Mioceno Médio. Esse deve ser considerado um valor mínimo, pois não se conhece a idade do início do vulcanismo nessa montanha oceânica de $4 \mathrm{~km}$ de altura. Além disso, a velocidade de espalhamento da crosta tem variado consideravelmente no tempo e espaço (Brosena 1986, Cande et al. 1988), mas esse valor é compatível com a taxa de expansão média da placa obtida por outros investigadores (Brosena op. cit., Cande et al. op.cit., Ferrari e Riccomini 1999). Ela justifica a suposição acima sobre a origem da cadeia de Fernando de Noronha com o arquipélago em sua terminação mais nova ainda não destruído pela erosão, bem como sua admitida correlação com o distrito alcalino de Fortaleza.

Pela identidade petrográfica, química e idades semelhantes às de Fernando de Noronha e Fortaleza, enfatizadas por Fodor et al. (1998) e outros, as intrusões alcalinas do Rio Grande do Norte também parecem atribuíveis à fusão do manto superior no
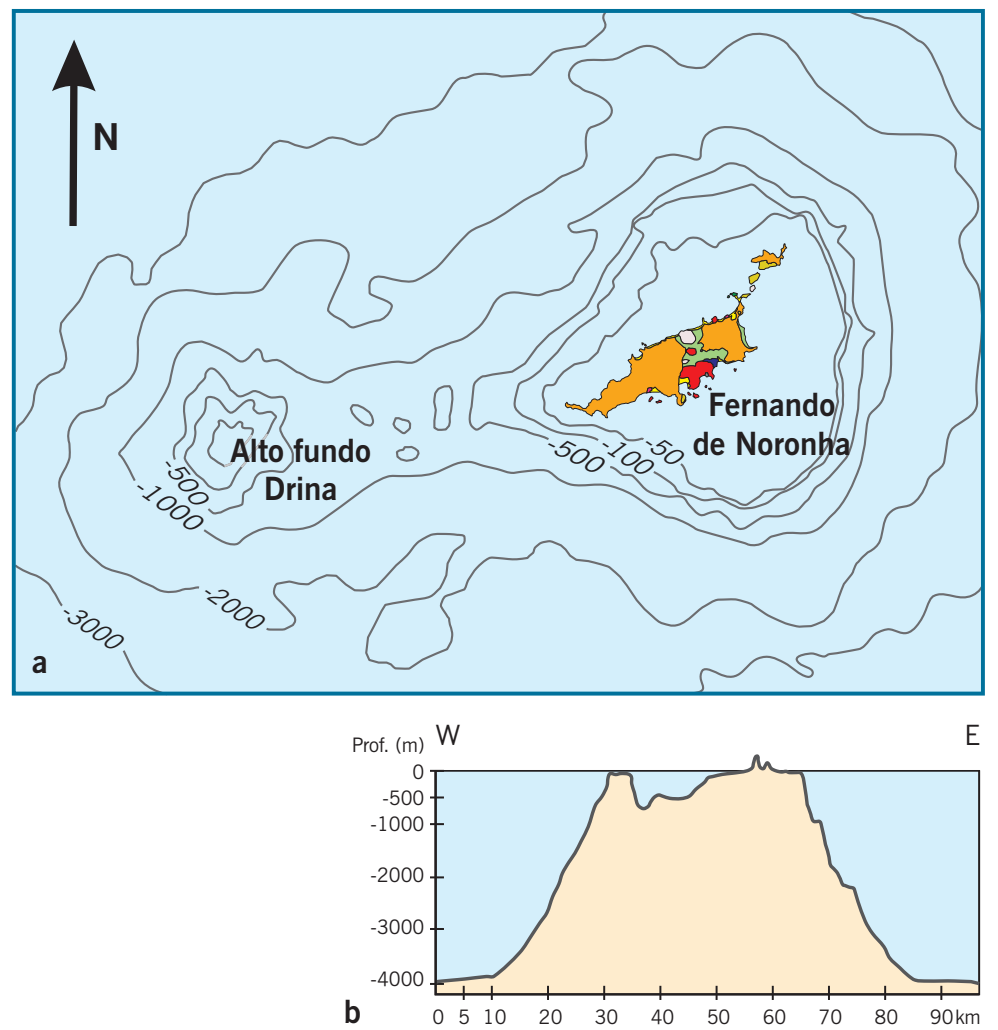

Figura 5 - Mapa batimétrico ao redor do Arquipélago de Fernando de Noronha e do alto fundo Drina adjacente (a); (b) perfil esquemático da ampla montanha, cuja base sustenta elevação de mais de $4.000 \mathrm{~m}$ de altura sobre o assoalho oceânico (modificado de Teixeira et al. 2003) evento tectono-térmico meso-eocênico, pois a rocha alcalina datada mais antiga acusou $47 \pm 01 \mathrm{Ma}$ (Mizusaki et al. 2002), valor equiparável à do distrito alcalino de Fortaleza. O efeito do hotspot Potiguar não se estendeu ao oceano formando cadeia como a de Fernando de Noronha por não existir uma zona de fratura oceânica adentrando essa região que canalizasse o magma, como ocorreu no Ceará.

Fernando de Noronha, a mais bela ilha brasileira, tem $\pm 16,4 \mathrm{~km}^{2}$ sendo a maior do arquipélago homônimo e das ilhas oceânicas nacionais. Este constitui a pequenina parte emersa de uma gigantesca montanha vulcânica submarina com aproximadamente $75 \mathrm{~km}$ de maior diâmetro na base alongada a leste-oeste, repousando no assoalho oceânico a cerca de $4.000 \mathrm{~m}$ de profundidade (Fig. 5). Outra elevação dessa montanha é o chamado alto fundo Drina, situado a $23 \mathrm{~km}$ a oeste do arquipélago, tendo seu cimo subnivelado em torno de $60 \mathrm{~m}$ de profundidade. O arquipélago compõe-se da ilha principal e de outras 18 pequenas ilhas que se elevam de uma reduzida plataforma insular que trunca o edifício vulcânico a menos de $120 \mathrm{~m}$ de profundidade. $\mathrm{O}$ Morro do Pico (Fig. 4), um domo da ilha Fernando de Noronha, é seu mais alto relevo, erguendo-se a $321 \mathrm{~m}$ de altitude. As rochas do arquipélago são vulcânicas e subvulcânicas subsaturadas, acentuadamente sódico-alcalinas. Representam dois episódios vulcânicos separados por um hiato erosivo. $\mathrm{O}$ mais antigo originou a Formação Remédios, que tem idades isotópicas datadas por Cordani (1970), do Mioceno Médio, $\pm 12 \mathrm{Ma}$. Constitui-se de piroclastos, maiormente ligados ao vulcanismo fonolítico, penetrados por diques, plugs e domos de fonólito, álcali-basalto, traquiandesito e outras rochas básicas e ultrabásicas cuja nomenclatura complexa foi atualizada por Ulbrich (1994). Após sofrer erosão durante fase de quietude do vulcão, que destruiu a maioria das rochas efusivas equivalentes a essas intrusivas e expôs em relevo os grandes corpos 
fonolíticos, seus restos foram recobertos pela Formação Quixaba, para a qual Cordani (op. cit.) encontrou valores radiométricos de 6,64 a 1,81 Ma, correspondentes ao Mioceno Superior a final do Plioceno $^{2}$. É esta formação em maior parte constituída de derrames e piroclastos de composição ankaratrítica [uma variedade de olivina melanefelinito contendo biotita], mas são referidos diques de nefelinito. Os derrames ankaratríticos sustentam dois planaltos de relevo escalonado e assim como os de basanito constituem pequenas ilhas. Almeida (1955) distinguiu uma formação que supôs ser mais nova, consituída pelo derrame de nefelina basanito da ilha de São José e duas ilhotas vizinhas. Ulbrich (op. cit.) e Ulbrich e Ruberti (1994), tendo descoberto uma pequena chaminé vulcânica de basanito penetrando os ankaratritos da baía do Sancho atribuíram a rocha da ilha de São José à Formação Quixaba. Cordani (1970) datou por K/Ar o nefelina basanito de São José, obtendo três valores entre cerca de 8,1 e 9,5 e outro de 21,9 Ma. Essa rocha, contudo, possui abundantes xenocristais de olivina e xenólitos angulosos a sub-arredondados de dunito que atingem 20 centímetros de diâmetro. Determinando a idade deles por $\mathrm{Rb} / \mathrm{Sr}$ encontrou $360 \mathrm{Ma}$, suportando sua origem mantélica. Essas inclusões estranhas contaminando a rocha põem em dúvida a antigüidade fornecida pela datação. Ela e suas inclusões merecem melhor estudo.

Com o término do vulcanismo e as grandes oscilações glácio-eustáticas pleistocênicas foi elaborada a plataforma insular, nela restando formas de erosão mantidas pelos corpos rochosos mais resistentes, sobretudo fonólitos, ankaratritos e basanitos. A grande regressão do mar ligada ao último estádio glacial causando ampla exposição da plataforma, especialmente a sueste onde ela é mais larga, propiciou o desenvolvimento de um campo de dunas tangidas pelos ventos alísios de SE. Sendo suas areias constituídas de grãos de carbonato de cálcio de origem biogênica - pois quartzo é quase inexistente nas ilhas - vieram a se consolidar originando os calcarenitos da Formação Caracas. Com a subida do nível marinho constituíram-se as ilhas nas rochas deixadas em destaque pela erosão da plataforma, as praias, recifes de algas calcárias e dunas de beira-mar atuais.

2 Adotamos a Escala de Tempo Geológico Internacional de Gradstein e colaboradores (2004).

\section{Atol das Rocas}

O Atol das Rocas é uma elevação da cadeia de Fernando de Noronha situada a $145 \mathrm{~km}$ a oeste do arquipélago homônimo. É uma construção holocênica datada por ${ }^{14} \mathrm{C}$, edificada predominantemente por algas coralinas sobre pequena parte da extensa plataforma cimeira, hoje situada entre 20 a $40 \mathrm{~m}$ de profundidade (Ottmann 1963), do que seria originalmente um guyot semelhante a outros grandes bancos da cadeia, mas cuja idade relativamente nova e subsidência suficientemente lenta permitiram a sobrevivência da flora de algas calcárias que o recobrem. A espessura mínima do calcário de recife, onde avaliada por investigação sísmica, é de $11,7 \mathrm{~m}$, tendo uma perfuração penetrado $11,6 \mathrm{~m}$ sem alcançar seu embasamento (Kikuchi 2002). Alongado na direção leste-oeste como o monte vulcânico que o suporta, o atol tem somente $7,5 \mathrm{~km}^{2}$ e 3,7 km de comprimento. Na maré alta só emergem duas pequenas ilhas e alguns cabeços calcários de origem algálica atestando nível pretérito do mar a \pm 2 ou 2,5 $\mathrm{m}$ acima do atual (Ottmann 1963). Nenhuma rocha vulcânica está exposta. Arenito eólico holocênico e algumas dunas ativas e sedimentos detríticos marinhos e lacustres ocorrem localmente.

\section{Ilha da Trindade}

A Cadeia Vitória-Trindade inicia-se no talude continental ao largo da capital capixaba a 175 quilômetros da costa. Perlonga em seu início a borda sul da saliência da plataforma continental representada pelo banco dos Abrolhos. É constituída por uma série linear de guyots e montes submarinos com descontinuidades, dispostos entre os paralelos $20^{\circ}$ e $21^{\circ} \mathrm{S}$ (Fig. 6). Foi identificada por Almeida (1960) e suposta como vulcânica, o que foi comprovado por Guazelli e Carvalho (1978). Constituem-na os bancos Besnard, Vitória, Congress, Champlaine, Montague, Jaseur, Columbia, Davies e Dogaressa, além de montes menores, terminando na ilha de Trindade e arquipélago Martin Vaz. Vários desses relevos submarinos têm forma alongada próxima da direção geral leste-oeste da cadeia, decorrente da intrusão do magma na zona de fratura assim orientada, com segmentação e desvios locais devidos a esforços que deformaram a placa, analisados por Ferrari e Riccomini (1999). Seus cimos submersos mais elevados foram aplainados pela erosão 

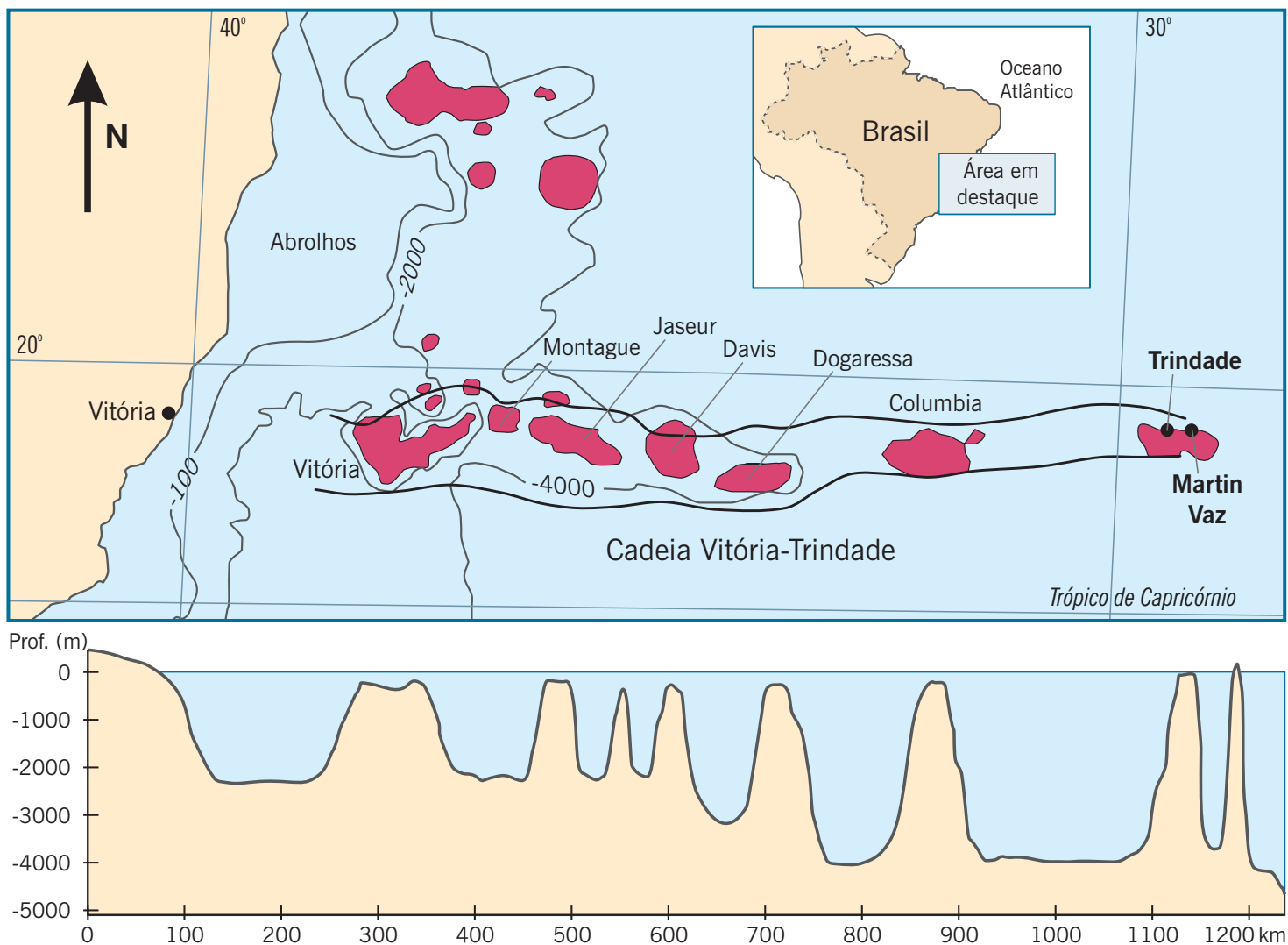

Figura 6 - Mapa batimétrico ao longo da Zona de Fratura de Vitória-Trindade entre a costa, a Ilha da Trindade e o Arquipélago Martin Vaz (a); (b) perfil esquemático da cadeia de montanhas submarinas (modif. de Alves 1998)

marinha, cobertos por calcários biogênicos e hoje se apresentam em profundidades inferiores a 100 m. Os bancos Vitória, Jaseur, Davis e Congress têm profundidade de 55-70 m. (Gorini 1969). Seus topos subnivelados alcançam $48 \mathrm{~km}$ de diâmetro no banco Vitória, e 46 no Davies, processo de aplainamento que ainda não se completou nos dois mais orientais, Trindade e Martin Vaz, que suportam ilhas destacadas. A cadeia, com interrupções e reduzidos relevos locais, tem cerca de $1000 \mathrm{~km}$ de extensão, alcançando o meridiano $29^{\circ} \mathrm{W}$. Foi proposto por Guazelli e Carvalho (1978), com base em perfis sísmicos transversais, que a cadeia se inclui na que denominaram Zona de Fratura de Vitória-Trindade, que se estende pelo menos ao meridiano de $19^{\circ} \mathrm{W}$, já no flanco da Dorsal Médio-Atlântica, até onde esses pesquisadores dispunham de levantamentos sísmicos. Sua extensão para leste de Trindade foi recentemente mapeada por Alves et al. (2002) que referem ter ela prosseguimento para a costa africana após atravessar a Dorsal MédioAtlântica e nela produzir pequeno deslocamento de seu eixo em torno de 6 quilômetros. Essas pesquisadoras usaram a denominação Zona de Fratura
Trindade-Hotspur. Segundo Guazelli e Carvalho (1978) o denominado Alto de Vitória, que na plataforma continental separa por falhas verticais as bacias sedimentares de Espírito Santo e Campos (Bacoccoli e Morales 1973), acha-se incluído nessa zona de fratura. É de notar a semelhança com o Alto de Fortaleza na Zona de Fratura Fernando de Noronha separando na plataforma continental as bacias do Ceará e Potiguar. Examinando imagens de satélite da margem continental emersa adjacente ao Alto de Vitória, Guazelli e Carvalho (1978) reconheceram fraturas orientadas em direção leste-oeste e dela vizinhas, portanto discordantes das direções estruturais orientadas a NNE-SSW observadas no embasamento pré-cambriano, e que se equiparam às que Costa et al. (2002) identificaram recentemente na região de Fortaleza. Admitiram que tais orientações refletem a associação desse alto à Zona de Fratura de Vitória-Trindade. Sua extensão mais para o interior do continente além de uma centena de quilômetros foi por Guazelli e Carvalho (1978) considerada como difícil de comprovar e altamente especulativa. São desconhecidas intrusões alcalinas no continente emerso que, à 


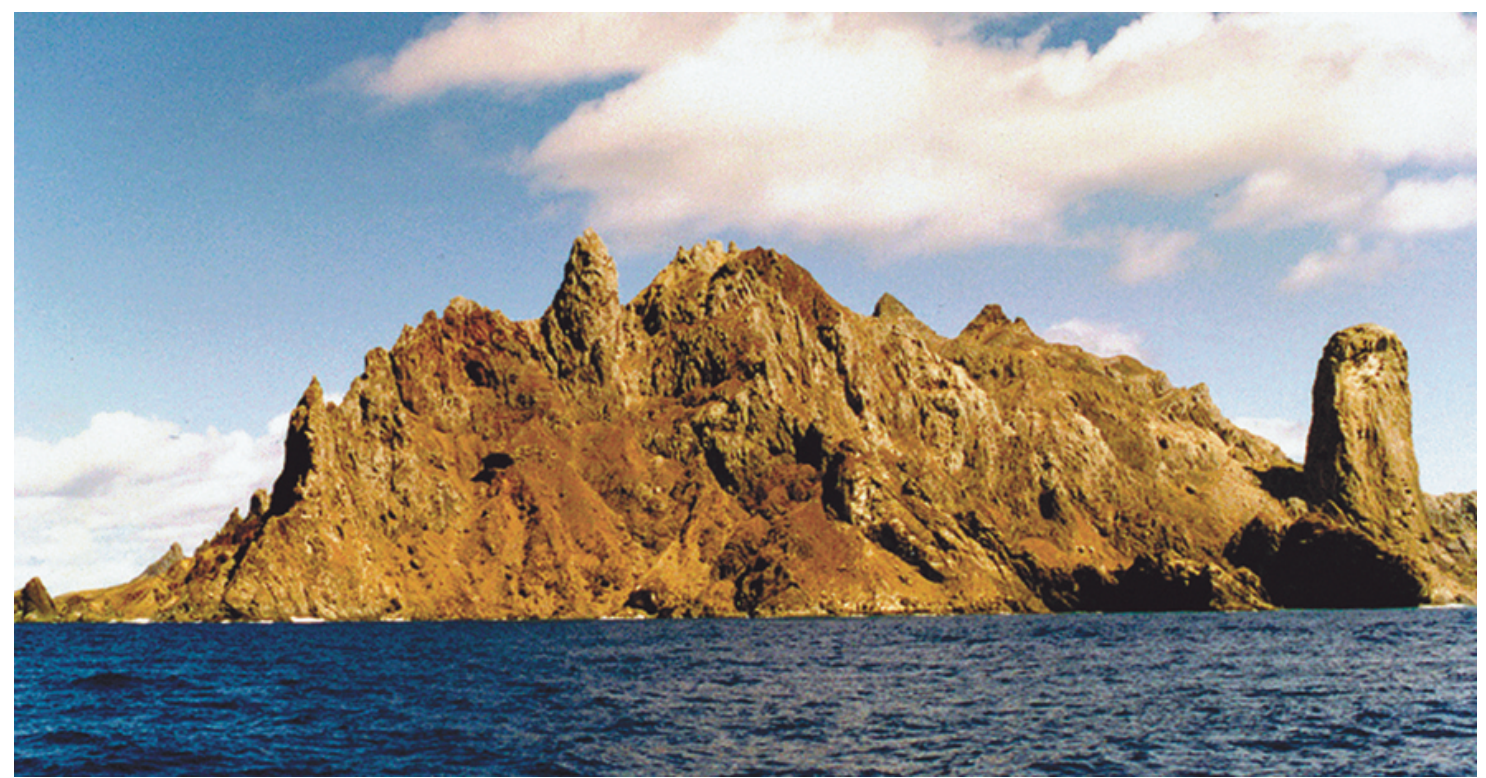

Figura 7 - Ilha da Trindade vista de sudoeste, onde se observam o relevo acidentado, os grandes diques fonolíticos escuros à beira-mar e o neck fonolítico do Morro do Monumento, à direita. (Foto Ulbrich et al., 2004)

semelhança das de Fortaleza, possam ser seguramente atribuídas ao hotspot que teria originado a cadeia vulcânica, mas elas supostamente se iniciam com o banco Besnard a cerca de $170 \mathrm{~km}$ ao largo de Vitória, no talude continental.

A Cadeia Vitória-Trindade reflete importante atividade tectono-magmática oceânica cenozóica realizada em falhas reativadas ao longo da referida zona de fraturas, com desnivelamentos do assoalho oceânico e formação de relevos vulcânicos já quase todos arrasados pela erosão marinha. Subsistem como ilhas, Trindade e o arquipélago de Martin Vaz no extremo oriental da cadeia, à semelhança de Rocas e Fernando de Noronha em relação à cadeia desse nome, sugerindo origem idêntica para ambas. A extensão dos cimos dos guyots em que foi transformado o arquipélago vulcânico do trecho ocidental da Cadeia Vitória-Trindade é muito maior que o diâmetro da plataforma de abrasão marinha à volta do edifício vulcânico de Trindade, que incluindo a ilha não ultrapassa $14 \mathrm{~km}$. O vulcanismo nela esteve ativo até o Holoceno. Tais fatos sugerem que o vulcanismo na cadeia progrediu no sentido oeste-leste, à medida que a Placa Sul-Americana se desloca para oeste com o espalhamento da crosta oceânica e a zona de fratura teria passado sobre um hotspot como foi sugerido por alguns autores (v.g. Minster et al. 1974). Burke e Dewey ainda em 1973 haviam suposto a presença atual de uma pluma mantélica sob Trindade e Martin Vaz cujo traço proviria da região das rochas alcalinas do Rio de
Janeiro. Como acima referido, a presença de tal pluma mantélica profunda, por muitos admitida $(v \cdot g$. Thompson et al. 1995, Gibson et al. 1997, Siebel et al. 2000), não é necessária. Um hotspot do tipo andersoniano poderia ter-se originado e fixado no manto superior sob a margem continental de litosfera adelgaçada e fraturada próximo ao limite com a oceânica, formando-se a cadeia na zona de fratura reativada no decorrer da deriva da placa, à semelhança do suposto para a Cadeia Fernando de Noronha. Fodor et al. (1989) apontam algumas semelhanças geoquímicas entre os basaltos eocênicos do banco dos Abrolhos e as vulcânicas de Fernando de Noronha e Trindade, como a composição isotópica de $\mathrm{Sr}-\mathrm{Nd}$ e $\mathrm{Pb}$ e o alto teor em Ti das rochas de Trindade. Esses basaltos, de natureza toleítica a alcalina, formaram-se em ambiente vulcânico dominantemente submarino com eventuais exposições subaéreas (Conceição et al. 1996, Mohriak 2005), tendo surgido por ocasião do evento tectono-magmático eocênico a que já nos referimos, que movimentou as placas em ambiente global e reativou zonas de fratura; equivalem na comparação, ao magmatismo do distrito alcalino de Fortaleza porém manifestados em ambiente marinho. Entretanto, não são conhecidas em Abrolhos as rochas sub-saturadas em sílica e ricas em álcalis presentes nesse distrito. Ferrari e Riccomini (1999) calcularam a velocidade de deslocamento da Placa SulAmericana sobre a pluma de Trindade entre os paralelos $20^{\circ}$ e $21^{\circ} \mathrm{W}$ obtendo valor de $23,1 \mathrm{~km} / \mathrm{Ma}$, 
coincidente com o que calculamos para a região do paralelo $4^{\circ} \mathrm{S}$ entre o Eoceno Médio e o Mioceno Médio $(23,4 \mathrm{~km} / \mathrm{Ma})$.

Okal e Anderson (1975) reconheceram acentuado atraso na propagação das ondas sísmicas $\mathrm{S}$, compatível com alto grau de fusão parcial do manto, apoiando a citada sugestão de Minster e colaboradores, da presença de um hotspot sob Trindade. Foi verificada por Veloso e Machado Jr. (1986) a existência de microtremores na área a menos de $50 \mathrm{~km}$ da estação sismográfica nela operada pela Universidade de Brasília entre 1982 e 1985. Esses autores também obtiveram resultados sugerindo a existência de anomalias da velocidade sísmica localizadas unicamente abaixo da ilha, que poderiam ser indícios desse suposto hotspot. Em face dessas informações e inferências e à juventude do vulcão do Paredão cabe perguntar: acha-se o vulcanismo em Trindade definitivamente extinto ou encontra-se em passageira fase de quiescência?

Pesquisas modernas sobre petrologia e geoquímica dessas ilhas são apresentadas por Marques et al. (1999) e outros a que eles se referem. Weaver (1990), comparando a geoquímica de Trindade e Fernando de Noronha aponta várias semelhanças entre elas, algumas das quais diversas das demais ilhas do Atlântico, como o alto grau de alcalinidade e de sub-saturação em $\mathrm{SiO}_{2}$, sugerindo uma evolução petrogenética comparável, parecendo provável que também Trindade e Martin Vaz tenhamse originado de um hotspot andersoniano, ainda presente sob elas.

A Diretoria de Hidrografia e Navegação (DHN) do Ministério da Marinha instalou em 1957 uma base de pesquisas científicas para dar apoio às pesquisas brasileiras para o Ano Geofísico Internacional (AGI-1957/1958). Graças às facilidades que então nos foram proporcionadas pela DHN, DNPM e CNPq fomos conduzidos a essa pequena e remota ilha pelo navio-escola Almirante Saldanha, acompanhados pelo engenheiro Shiguemi Fujimori e o então nosso aluno Tibério Cescon, nela tendo permanecido durante os dois primeiros meses de 1958. Em 1965 retornamos à ilha em companhia do prof. U. G. Cordani. A pequena e remota ilha é o cimo emerso de uma grande montanha vulcânica alongada, com $67 \mathrm{~km}$ de maior diâmetro basal, que repousa a $\pm 5.000 \mathrm{~m}$ de profundidade sobre assoalho oceânico com idade de $\pm 80,17$ Ma estimada pelas anomalias magnéticas da crosta em que se apóia (Kent e Gradstein 1986, af. Cande et al. 1988). Acha-se situada na latitude $20^{\circ} 30^{\prime} \mathrm{S}$ e longitude de $29^{\circ} 22^{\prime}$ W. Embora tenha aproximadamente só 9,28 $\mathrm{km}^{2}$ de área emersa nela existem três picos elevados entre 570 e $640 \mathrm{~m}$, sendo Desejado o mais alto. Com quase $6 \mathrm{~km}$ de altura é o monte Trindade um dos mais altos do Atlântico Sul (Fig. 6).

Constitui-se a ilha de derrames e intrusões de rochas altamente sódico-alcalinas e acentuadamente sub-saturadas em sílica, e piroclastos diversos, formados entre o Plioceno Médio e o Holoceno (Cordani 1970, Hansen et al. 1998). Recifes de algas, estreitas praias e dunas locais, reduzidos depósitos fluviais à beira-mar e numerosos cones e aventais de talude são o que também nela existe, porém ela é quase toda constituída de rochas vulcânicas e subvulcânicas. Em Trindade Almeida (1961) reconheceu cinco conjuntos vulcânicos sendo os quatro mais novos claramente discerníveis enquanto o quinto, o Complexo de Trindade, é um conjunto heterogêneo de rochas piroclásticas variadas associadas principalmente ao vulcanismo fonolítico. Expõe-se nas vertentes de quase toda a ilha, sendo penetrado por numerosas intrusões de fonólitos, traquiandesitos, nefelinitos e diversas ultrabásicas alcalinas. Destacam-se 16 grandes intrusões fonolíticas de contornos subcirculares a elípticos que se sobressaem no relevo, representando domos endógenos com até cerca de $400 \mathrm{~m}$ de diâmetro, plugs, necks e muitas dezenas de diques. As intrusões fonolíticas, de diversas composições químicas e mineralógicas (Marques et al. 1999), suportam os espetaculares necks e grandes diques que chegam a alcançar dezenas de metros de espessura, expostos pela erosão que modela o acidentado relevo da ilha (Fig. 7). Acusaram idades radiométricas K/Ar obtidas por Cordani (1970) entre 2,3 e 2,9 Ma caracterizando o Meso a Neoplioceno, valores confirmados por Valencio e Mendía (1974). A rocha mais antiga da ilha datada por Cordani e Blazekovik (1970) é um dique de basanito que acusou $4 \pm 01$ Ma. Desconsideramos a datação do fonólito do Pico Nossa Senhora de Lourdes $(6.4 \pm 3.5 \mathrm{Ma})$ referida por Valencio e Mendía por ter acusado erro muito grande devido à amostra conter 91,9\% de argônio atmosférico. A Formação Desejado constitui-se de derrames de fonólito e nefelinito com intercalações de camadas de piroclastos de composição equivalente, dispostos sobre superfície de erosão do Complexo de Trindade. Chega a alcançar cerca de $250 \mathrm{~m}$ de espessura, expondo-se no alto das grandes escarpas, constituindo na movimentada região axial da ilha seus mais elevados picos que teriam dado o nome à ilha: Desejado, Trindade e São 
Bonifácio. Sua idade radiométrica indica valores entre 2,63 e 1,50 Ma, equivalentes ao Plioceno Médio e Pleistoceno Inferior. É bem clara a discordância erosiva com as rochas do Complexo. Seguiu-se um hiato no vulcanismo que perdurou cerca de 1,3 Ma, após o qual ele foi retomado em meados do Pleistoceno, quando se iniciou a emissão de lavas ultrabásicas alcalinas, variedades de melanefelinito, em três episódios bem distintos, o primeira dos quais constituiu a Formação Morro Vermelho. Erupção de ankaratritos e olivina melanefelinitos realizou-se numa região de diques próxima ao Morro Vermelho, no alto vale do córrego Vermelho na região central da ilha. As lavas, muito fluidas, escoaram por esse vale em direção ao litoral nordeste, preenchendo-o com espessura superior a $230 \mathrm{~m}$ de derrames e piroclastos que formam baixo planalto inclinado para o litoral norte. Posterior captura do córrego para o litoral sueste causou o entalhe erosivo de um cânion em cujas escarpas a formação pode ser bem observada, e que se abre para o grande leque aluvial da praia do Príncipe. Datações K/Ar apresentadas por Cordani (1970) indicaram que a erupção é mais nova que 170.000 anos.

O presente estado de erosão da ilha já havia sido alcançado quando no alto vale do córrego do Valado que desce a acentuada vertente norte irromperam piroclastos e derrames de lava de natureza olivina melanefelinítica que constituem a Formação Valado. Os derrames escoaram vale abaixo, intercalando-se nos grossos clastos do cone aluvial que por ele se estendiam ao mar. A lava, extremamente fluida, formou derrames que chegam a ter centímetros de espessura. Durante a erupção o cone aluvial continuava a se desenvolver e os produtos vulcânicos alternavam-se com os grossos fragmentos que tombavam das escarpas. Camada única de tufos lapilíticos e cineríticos, certamente posterior ao vulcanismo Morro Vermelho, apresenta-se intercalada em outras acumulações detríticas, em cones e aventais de talude. Isso bem se observa no referido cone aluvial do baixo córrego Vermelho. $\mathrm{Na}$ foz deste, no talude da falésia inativa à beira-mar na praia do Príncipe, observa-se camada de piroclastos da Formação Valado com 0,4 m de espessura, intercalada no cone aluvial formado principalmente por detritos de erosão da Formação Morro Vermelho, comprovando claramente a maior antigüidade desta. No final da praia, junto ao pico Pão de Açúcar, os detritos do cone e sua intercalação vulcânica, expostos na vertente da falésia, recobremse em acentuada discordância angular por piroclastos emitidos pelo vulcão do Paredão. Tendo em vista o grau de evolução geomorfológica avançada da ilha por ocasião do vulcanismo Valado, bem como sua posterioridade em relação ao vulcanismo Morro Vermelho, como observado nesse cone aluvial, parece possível ter sido pós-glacial o vulcanismo Valado. Por ser tão novo sua datação radiométrica não pôde ser feita por Cordani (1970). Valencio e Mendía (1974) referem datação K/Ar de $1,2 \pm 1,0$ Ma realizada por E. Linares no Instituto Nacional de Geologia Isotópica da Universidade de Buenos Aires, Argentina, para o derrame dessa formação na ponta homônima. Desconsideramos esta datação, não só pelas condições geológicas da ocorrência que examinamos no campo como pelo elevado erro resultante da determinação realizada em amostra contendo 99,2\% de argônio atmosférico. A Formação Valado é claramente mais nova que Morro Vermelho, e anterior à erupção do vulcão do Paredão. Durante o levantamento geológico identificamos o morro do Paredão na terminação sueste da ilha como sendo a parte restante de um cone vulcânico, único existente no Brasil, em destruição pelo mar, porém atualmente dela protegido por terraço de $\pm 3,5 \mathrm{~m}$. Testemunha certamente a última erupção havida na ilha e derradeira atividade magmática em território brasileiro. Ainda deixa perceber restos de sua superfície original assim como da borda circular da cratera. O cone formouse pelo acúmulo de piroclastos variados: tufos lapilíticos e cineríticos contendo bombas rotacionais, blocos, agregados e aglutinados de lava melanefelinítica, basanítica e tefrítica (classificação química, Marques et al. 1999), que se acumularam em camadas radialmente inclinadas para a periferia do cone a partir da cratera. Ainda subsistem restos de camadas inclinadas da borda da cratera para seu interior. A lava muito fluida e carregada de gases escoava para norte, exposta hoje no chamado parcel das Tartarugas, arrasado pelo terraço marinho de $\pm 3,5$ $\mathrm{m}$. O cone piroclástico elevou-se da plataforma insular então parcialmente seca para atingir pouco mais de $200 \mathrm{~m}$ de altura. A emissão da lava era grandemente do tipo fire fountaining, o magma lançado ao espaço em porções ainda líquidas, incandescentes. Suas cinzas, tangidas pelos ventos de leste, espalharam-se pela ilha, e ainda há restos de suas camadas, espessos de até quatro metros, a quase 2.000 metros de distância, à borda leste do pico das Grazinas e pequenas quantidades delas, em muitos lugares da ilha, sempre em camada única mostrando que a erupção foi continuada e breve. 
Vulcões modernos do tipo do Paredão podem erguer seus cones em semanas ou meses, tornando-se então inativos. Tal seria Paredão. Não existem às suas faldas indícios de terraços marinhos elevados a vários metros. Unicamente notamos persistente terraço próximo de $3,5 \mathrm{~m}$ de altura atribuível ao Holoceno, relacionado ao chamado ótimo climático ou intervalo hipsotermal, o que nos leva a supor que Paredão seja holocênico, porém anterior a \pm 5.000 anos.

\section{Arquipélago de Martin Vaz}

O Arquipélago de Martin Vaz situa-se a $47 \mathrm{~km}$ a leste de Trindade, erguendo-se do mesmo monte de que esta se eleva, a se julgar pela batimetria (NGDC 1994). Consiste de uma ilha maior com apenas $800 \mathrm{~m}$ de comprimento, 500 de largura e 175 de altura, e duas menores situadas a norte e a sul dela, além de escolhos (Gorini e Carvalho 1984). Tem sido geologicamente pouco investigada por ser rodeada de rochedos e escarpas inacessíveis. Belas fotografias contidas no livro do botânico Alves (1998) dão idéia dessa dificuldade. O nome do arquipélago vem de um suboficial do explorador e navegador francês conde de La Pérouse, que em 1768 morreu ao tentar escalá-la, junto com um marinheiro que também morreu. Deve ter constituição geológica semelhante à de Trindade, com plug fonolítico intrusivo em piroclastos e derrames de lava no alto. Uma datação de fonólito efetuada por Cordani (1970) acusou idade inferior 0,75 Ma e datação recente em outra amostra dessa rocha indicou 1,1 0,5 Ma (Hansen et al. 1998). Siebel et al. (2000) apresentam análises químicas, incluindo elementos traços, de derrame basanítico e plug fonolítico da ilha maior. Duas amostras coletadas à beira-mar nessa ilha foram classificadas por Scorza (1964) como ankaratrito e haüynito.

\section{Conclusões}

Em conclusão, quatro das ilhas e arquipélagos oceânicos brasileiros tiveram origem idêntica. Constituem a parte emersa da terminação oriental de duas extensas cadeias vulcânicas de orientação geral leste-oeste hoje arrasadas pela erosão e submersas. Surgiram essas cadeias em zonas de fratura reativadas no Eoceno Médio, que se estendem à margem continental, através das quais se reali- zou extravasamento de magma proveniente de hotspots fixos no manto superior durante a deriva da placa litosférica para oeste causada pelo espalhamento da crosta oceânica. As ilhas representam o topo emerso de grandes montes vulcânicos do extremo oriental dessas duas cadeias. $\mathrm{O}$ atol das Rocas é um desses montes, mas nele já não afloram rochas vulcânicas, porém calcários biogênicos que as recobrem. O arquipélago de São Pedro e São Paulo, entretanto, tem origem inteiramente diversa, emergindo no trecho transformante ativo de uma cadeia de zona de fratura no sítio em que esta secciona o rift-valley axial da Dorsal MesoAtlântica e expondo protrusão de rochas mantélicas sem que aflorem vulcânicas emersas, mas sim submersas. Verifica-se que a estrutura tectônica da litosfera oceânica teve decisiva influência na origem e localização geográfica de todas elas.

\section{Agradecimentos}

O autor agradece ao Prof. Dr. Celso Dal Ré Carneiro a revisão que fez do texto e as sugestões apresentadas que muito o enriqueceram, assim como a execução das figuras, para a qual contribuiu o Geól. Virginio Mantesso Neto, e a versão do sumário para o inglês. Agradece igualmente aos revisores anônimos da revista por suas observações e correções, ao Prof. Dr. Benjamin Bley de Brito Neves pelo fornecimento de bibliografia inédita, ao filho Fernando Luiz e à nora Gisele que lhe facultaram continuar a freqüentar bibliotecas para poder executar este trabalho.

\section{Referências}

Almeida F.F.M.de. 1955. Geologia e Petrologia do Arquipélago de Fernando de Noronha. Rio de Janeiro, DGM/DNPM. 181p. (Monografia 13).

Almeida F.F.M.de 1960. Quelques aspects sousmarins au large de la cote brésilienne. In: IUGS, Int. Geol. Congr., 21, Copenhagen, 1960. Actas..., Copenhagen, parte 10, p. 23-28.

Almeida F.F.M.de. 1961. Geologia e Petrologia da Itha da Trindade. Rio de Janeiro, DGM/DNPM. 206p. (Monografia 18).

Almeida F.F.M.de, Carneiro C.D.R., Machado Júnior D.L., Dehira L.K. 1988. Magmatismo pósPaleozóico no Nordeste Oriental do Brasil. Rev. Bras. Geoc., 18(4):451-462. 
Alves E.C., Maia M., Wiedemann, C.M. 2002. Zona de fratura Trindade-Hotspur no Atlântico Sudoeste e suas implicações tectônicas. In: Cong. Bras. Geol., 41, João Pessoa. 2002. Anais... João Pessoa. SBG. p. 616.

Alves R.J.V. 1998. Ilha da Trindade \& Arquipélago de Martin Vaz: Um Ensaio Geobotânico. Rio de Janeiro: Serv. Doc. Mar: 144.

Anderson D.L. 2000. The thermal state of upper mantle; no role for mantle plumes. Geoph. Res. Lett., 27:3623-3626.

Bacoccoli G., Morales R.G. 1973. Bacia do Espírito Santo: Geologia e perspectivas petrolíferas. In: Curso de atualização de geologia de petróleo (CAGEP- 1) Anais... Rio de Janeiro. Petrobrás. Dexpro.Divex, 1973, 2. Bacias da costa leste do Brasil, geologia e perspectives petrolíferas.

Bonatti E. 1973. Origin of offsets of the Mid-Atlantic Ridge in fracture zones. J. Geol. 81:144-156.

Bonatti E. 1976. Serpentinite protrusions in the oceanic crust. Earth. Planet. Sci.Lett., 32:107-113.

Braga A.P.G. et al. 1981. Geologia da região nordeste do Estado do Ceará. Projeto Fortaleza. Brasília: DNPM/CPTM. 123p. (Geologia 12, Seção Geologia Básica 9).

Brozena J.M. 1986. Temporal and spatial variability of seafloor spreading in the northern South Atlantic. J. Geoph. Res., 91(B1):497-510.

Bryan G.M., Kumar N., Castro P.J.M.de. 1972 . The north brazilian ridge and the extension of equatorial fracture zones into the continent. In: Cong. Bras. Geol., 41, João Pessoa.1972. Anais... João Pessoa. SBG. p. 133-143.

Burke K., Dewey. J.F. 1973. Plume-generated triple junctions: key indicators in applying plate tectonics to old rocks. J. Geol., 81:406-433

Campos T.F.C., Srivastava N.K., Macambira M.J.B., Petta R.A., Amaral R., Virgens Neto J.das. 2002. A Formação São Pedro e São Paulo: uma nova unidade litoestratigráfica quaternária do Atlântico Equatorial brasileiro. In: Cong. Bras. Geol., 41, João Pessoa. 2002. Anais... João Pessoa. SBG. p. 353.

Campos T.F.C., Virgens Neto J.das, Sirivastava N.K., Petta R.A., Hartmann L.A., Moraes J.F.S.de, Mendes L., Silveira S.R.M. 2005. Arquipélago de São Pedro e São Paulo. Soerguimento tectônico de rochas infracrustais no Oceano Atlântico. $<$ http//www.unb.br/ig/sigep/sitio 002/sitio 002.pdf>

Cande S.C., LaBrecque J.L., Haxby W.F. 1988. Plate kinematics of the South Atlantic: chron C34 to present. J. Geoph. Res., 93(B11):13.492-13.479.
Carneiro C.D.R., Hamza V.M., Almeida F.F.M.de. 1989. Ativação tectônica, fluxo geotérmico e sismicidade no Nordeste Oriental brasileiro. Rev. Bras. Geoc., 19(3):310-322.

Conceição J.C.J., Misuzaki A.M.P., Alves D.B., Szatmari P. 1996. Controle tectônico do magmatismo do Complexo Vulcânico de Abrolhos, Bacia do Espírito Santo. In: Cong. Bras. Geol., 39, Baln. Camboriu, 1996. Anais... Baln. Camboriu: SBG. v. 5, p. 384-387.

Cordani U.G. 1970. Idade do vulcanismo no Oceano Atlântico Sul. Bol. Inst. Geoc. Astron. USP. São Paulo, 1:9-75.

Cordani U.G., Blazekovic A. 1970. Idades radiométricas das rochas vulcânicas de Abrolhos. In: Cong. Bras. Geol., 24, Porto Alegre. 1970. Anais... Porto Alegre: SBG. v. 3, p. 265-270.

Costa P.R.C., Antunes A.F., Sá E.F.J. de, Amaro V.E., Matos R.M.D.de. 2002. O registro da deformação mesozóica relacionada à abertura da margem equatorial atlântica no litoral do Estado do Ceará (Nordeste do Brasil): evidências a partir da análise de imagens orbitais e de afloramentos. In: Cong. Bras. Geol., 41, João Pessoa. 2002. Anais... João Pessoa. SBG. p. 623.

Courtillot V., Davaille A., Besse J., Stock J. 2003. Three distinct types of hotspot in the Earth's mantle. Earth. Planet. Sci. Lett., 205:295-308.

Ernesto M. 2005. Paleomagnetism of the postPaleozoic alkaline magmatism in the Brazilian Platform: questioning the mantle-plume model. In: P. Comin-Chiaramonti \& C. B. Gomes, eds. Mesozoic to Cenozoic alkaline magmatism in the Brazilian Platform. São Paulo, Edusp/Fapesp. p. 689-705.

Ferrari A.L., Riccomini C. 1999. Campo de esforços plio-pleistocênico na Ilha de Trindade (Oceano Atlântico Sul, Brasil) e sua relação com a tectônica regional. Rev. Bras. Geoc., 29:195-202.

Fodor R.V., Mukasa S.B., Sial A.N. 1998. Isotopic and trace-element indications of lithospheric and asthenospheric components in Tertiary alkalic basalts, northeastern Brazil. Lithos, 43:197-217.

Gibson S.A., Thompson R.M., Weska R.K., Dickin A.P., Leonardos O.H. 1997. Late Cretaceous riftrelated upwelling and melting of the Trindade starting mantle plume head beneath western Brazil. Contrib. Mineral. Petrol., 126:303-314.

Gibson S.A, Thompson R.N., Leonardos O.H., Dickin A.P., Mitchell J.G. 1995. The Late Cretaceous impact of the Trindade mantle plume: evidence for large-volume, mafic, potassic magmatism in SE Brazil. J. Petrol., 26:189-229. 
Gorini M.A. 1969. Geologic observations on the "Comissão Oceanográfica Leste I" aboard the Research Vessel "Almirante Saldanha". An. Acad. brasil. Ciênc. Rio de Janeiro, 41:642R-643R.

Gorini M.A., Carvalho J.C.de. 1984. Geologia da margem continental inferior brasileira e do fundo oceânico adjacente. In: Schobbenhaus C., Campos F.A., Derzi G.R., Asmus H.A. coords. 1984. Geologia do Brasil. Brasília. DNPM/MME: p. 473-489.

Gorini M.A, Bryan G.M. 1974. A semi-isolated basin off the northeast brazilian margin. Amer. Geoph. Union Trans., 55:278.

Gorini M.A, Bryan G.M. 1976. The tectonic fabric of the equatorial Atlantic and adjoining continental margins: gulf of Guinea to northeastern Brazil. An. Acad. brasil. Ciênc. Rio de Janeiro, 48 (Suplemento):101-119.

Gradstein F.M., Ogg J.G., Smith A.G., Bleeker W., Lourens L.J. 2004. A New Geologic Time Scale, with special reference to Precambrian and Neogene. Episodes, 27(3):83-100.

Guazelli W., Carvalho J.C. 1978. A extensão da zona de fratura de Vitória-Trindade no oceano e seu possível prolongamento no continente. Aspectos estruturais da margem continental leste e sudeste do Brasil. Rio de Janeiro. Petrobrás. p. 31-37. (Série Projeto Remac n. 4).

Guazelli W., Costa M.P.A. 1978 . Ocorrência de fosforita e de nódulos metálicos nos platôs do Ceará e de Pernambuco. Rio de Janeiro. Petrobrás. 1978. p. 7-14. (Série Projeto Remac n. 3).

Guimarães I.P., Sial A.N., Silva Filho A.F. 1982. Petrologia e geoquímica da província alcalina terciária Fortaleza, Ceará. In: Cong. Bras. Geol., 32, Salvador. 1982. Anais... Salvador, SBG. p. 577-588.

Hansen M.A.F., Viramonte J.G., Troian F.L., Mizusaki A.M. P., Becchio R., Fensterseifer H.C. 1998. Nuevas edades para el volcanismo de las isles Trindade y Martin Vaz, Brasil. Sixth International Meeting: Colima Volcano, México, 26.1-28.1, Abstracts, 125

Hekinian R., Juteau, T., Gràcia, E., Sichler, B., Sichel, S., Udintsev, G., Apprioual, R., Ligi., M. 2000. Submersible observations of Equatorial Atlantic mantle: The St. Paul Fracture region. Mar. Geoph. Resear., 21:529-560.

Hess, H.H. 1946. Drowned ancient islands of the Pacific Basin. Amer. J. Sci., 244, 772-791

Kent D.V., Gradstein F.M. 1986. A Jurassic to recent chronology. In: B.E. Tuchlke \& P.R. Vogt, eds. The Geology of North America: The Western Atlantic Region. Boulder, Geol. Soc. Amer.. (Série DNAG, 1)
Kikuchi R.K.P.de. 2002. Atol das Rocas, litoral do nordeste do Brasil. Sítios geológicos e paleontológicos do Brasil. SIGEP. Comissão Brasileira de Sítios Geológicos e Paleobiológicos. DNPM/CPRM, Brasília, 2002. p. 379-390.

Macciotta G., Almeida A., Barbieri M., Beccaluva L., Brotzu P., Coltorti M., Conte A., Garbarino C., Gomes C.B., Morbidelli L., Ruberti E., Siena E., Traversa G. 1990. Petrology of the tephritephonolite and cognate xenoliths of the Fortaleza district (Ceara, Brazil) Europ. J. Miner., 2:687-709.

Marques L.S., Duprè B., Piccirillo E.M. 1999. Mantle source compositions of the Paraná Magmatic Suíte (southern Brazil): evidence from trace element and $\mathrm{Sr}-\mathrm{Nd}-\mathrm{Pb}$ isotope geochemistry. $J$. Geod., 28:439-458.

Marques L.S., Ulbrich M.N.C., Ruberti E., Tassinari C.G. 1999. Petrology, geochemistry and Sr-Nd isotopes of Trindade and Martin Vaz volcanic rocks (Southern Atlantic Ocean). J. Volcan. Geoth. Res., 93:191-216.

Melson W.G., Hart S.R., Thompson G. 1972. St. Paul's Rocks, Equatorial Atlantic: petrogenesis, radiometric ages, and implications on sea floor spreading. Geol. Soc. Amer., Memoir, 132:241272.

Menard H.W. 1984. Origin of Guyots: The Beagle to Seabeam. J. Geoph. Res., 89(B-13):11.11711.123.

Minster J.B., Jordan, T.H., Molnar, P., Haines, E. 1974. Numerical modelling of instantaneous plate tectonics. Geoph. J. Res. Astron. Soc., 36:541576.

Miranda F.P., Liu C.C., Rodrigues J.E. 1986. Análise estrutural e tectônica do Pré-Cambriano adjacente às bacias de Barreirinhas e do Ceará, através de dados de sensores remotos. Rio de Janeiro. Petrobrás/Cenpes/MCT/INPE. 99p. (Rel. Tec. Cenpes 736).

Misuzaki A.M.P., Thomaz Filho A., Césero P.de. 1998. Age of the magmatism and the opening of the South Atlantic Ocean. Inst. Geoc., UFRGS, Porto Alegre. Pesquisas, 25(2):47-57.

Misuzaki A.M.P, Thomaz Filho A., Milani E.J., Césero P.de. 2002. Mesozoic and Cenozoic igneous activity and its tectonic control in notheastern Brazil. J. South Amer. Earth Sci., 15:183-198.

Mohriak W.U. 2005. Interpretação geológica e geofísica da Bacia do Espírito Santo e da região de Abrolhos: petrografia, datações radiométricas e visualização sísmica das rochas vulcânicas. Bol. Geoc. Petrobrás, 14:133-142. 
Morgan W.J. 1971. Convection plumes in the lower mantle. Nature, 230:42-43.

Morgan W.J. 1983. Hotspot tracks and the early rifting of the Atlantic. Tectonophysics, 94:123-139.

Nascimento D.A.do, Gava A., Pires I.L., Teixeira W. 1981. Geologia. In: PROJETO Radambrasil Folha SA. 24 Fortaleza: geologia, geomorfologia, pedologia, vegetação e uso potencial da terra. Brasília. MME/SG: 9-212 (Levantamento Recursos Naturais 21).

O’Connor J.M., Roex A.P.de. 1992. South Atlantic hot spot-plume system: 1-Distribution of volcanism in time and space. Earth Planet. Sci. Lett., 113:342-364.

Okal E.A., Anderson D.L. 1975. A study of lateral inhomogeneities in the upper multiple $\mathrm{ScS}$ traveltime residuals. Geoph. Resear. Lett., 2:313-316.

Ottmann F. 1963. "L' atol das Rocas" dans l'Atlantique sud tropical. Rev. Géog. Phys. Geol. Dinam. (2) V, fasc. 2:101-107.

Rao A.B., Sial A.N. 1972. Observations on alkaline plugs near Fortaleza city, Ceará State, Brazil. In: International Geological Congress, 24. Montreal, 1972. Proceedings. Montreal. Sec. 14:56-61.

Sadowski G.R. 1987. A possible relation between pulses of platform activation and plate kinematics. Tectonophysics., 143:43-57.

Schobbenhaus Filho C.F., Campos D.A., Derze G.R., Asmus H.E. 1981. Mapa Geológico do Brasil e da área oceânica adjacente, incluindo depósitos minerais, escala 1:2.500.000. Brasília, MME-DNPMDGM.

Scorza E.P. 1964. Duas rochas alcalinas das ilhas Martin Vaz. Rio de Janeiro, DNPM/DGM, Notas Preliminares e Estudos 121:1-7.

Sial A.N. 1987. The Tertiary alkaline province of Fortaleza, State of Ceará, Brazil: oxygene isotopes and REE- geochemistry. Geoch. Brasil, 1:41-51.

Siebel W., Becchio R., Volker F., Hansen M.A.F, Viramonte J., Trumbell R.B., Haase G., Zimmer M. 2000. Trindade and Martin Vaz Islands, South Atlantic: isotopic $(\mathrm{Sr}, \mathrm{Nd}, \mathrm{Pb})$ and trace elements constraints on plume related magmatism. South Amer. Earth Sci., 13:79-103.

Sykes L.R. 1978. Intraplate seismicity, reactivation of preexisting zones of weakness, alkaline magmatism, and other tectonism postdating continental fragmentation. Rev. Geophys. and Space Phys., 16(4):621-687.

Teixeira W., Cordani U.G., Menor E.A., Teixeira M.G., Linsker R. et al. 2003. Arquipélago Fernando de Noronha. O paraíso do vulcão. São Paulo:Terra Virgem Ed., 1-167.
Teixeira W., Tassinari C.C.G., Siga Jr. O. 1978. Interpretação geocronológica da folha AS-24 Fortaleza. Projeto Radambrasil, Natal, 18p.

Thomaz Filho A. 1983. Datações radiométricas de rochas ígneas básicas da bacia do Ceará. Rio de Janeiro. Petrobrás/Cenpes. (Rel. interno, Cenpes, 673-4462).

Thompson R.N., Gibson S.A., Mitchell J.G., Dickin A.P., Leonardos O.H., Brod J.A., Greenwood J.C. 1998. Migrating Cretaceous-Eocene magmatism in the Serra do Mar alkaline Province, SE Brazil: melts from the deflected Trindade mantle plume? J. Petrol., 39:1493-1526.

Ulbrich M.N.C., Ruberti E. 1992. Nova ocorrência de rochas basaníticas no arquipélago de Fernando de Noronha. In: Cong. Bras. Geol., 37, São Paulo. 1992. Bol. Res. Expand... São Paulo. SBG. p. 83-84.

Ulbrich M.N.C. 1994. Petrography of alkaline volcanic-subvolcanic rocks from the brazilian Fernando de Noronha archipelago, Southern Atlantic Ocean. Bol. Inst. Geoc. Univ. São Paulo. Série Científica., 24:77-94.

Ulbrich M.N.C., Marques L.S., Lopes R.P. 2004. As ilhas vulcânicas brasileiras: Fernando de Noronha e Trindade. In: V. Mantesso-Neto, A. Bartorelli, C.D.R. Carneiro, B.B.deB. Neves, coords. Geologia do Continente Sul-Americano: Evolução da Obra de Fernando Flávio Marques de Almeida. São Paulo: Beca. p. 555-573.

Valencio D.A., Mendía J.E. 1964. Paleomagnetism and $\mathrm{K}-\mathrm{Ar}$ age of some rocks of the Trindade Complex and the Valado Formation from Trindade Island, Brazil. Rev. Bras. Geoc., 4:124-132.

Vandoros P., Oliveira M.A.F. 1968. Sobre o fonólito de Mecejana, Ceará. An. Acad. brasil. Ciênc., 40(2):203-206.

Veloso J.A.V., Machado D.L. 1986. Estudos sismológicos na ilha da Trindade desenvolvidos pela estação sismológica da UnB. In: Cong. Bras. Geol., 34, Goiânia. 1986. Anais... Goiânia. SBG. v. 6, p. 2.608-2.613.

Weave B.L. 1990. Geochemistry of highlyundersaturated ocean island basalt suites from the South Atlantic Ocean: Fernando de Noronha and Trindade islands. Contrib. Mineral. Petrol., 105:502-515.

Wilson J.T. 1965. A new class of faults and their bearing on continental drift. Nature, 207:343-347.

Submetido em 23 de fevereiro de 2006. Aceito em 15 de junho de 2006. 